\title{
AS POLÍTICAS PÚBLICAS PARA O MEIO RURAL NO BRASIL E EM PORTUGAL E SUAS ABORDAGENS
}

\author{
PUBLIC POLICY FOR RURAL AREAS IN BRAZIL AND \\ PORTUGAL AND APPROACHES
}

\author{
Eliane Regina Francisco da Silva \\ Doutoranda em Geografia pela Universidade Estadual Paulista/Campus Presidente Prudente \\ lianecarvalho11@yahoo.com.br \\ Rosangela Aparecida de Medeiros Hespanhol \\ Docente dos Cursos de Graduação e Pós-Graduação em Geografia da Universidade Estadual \\ Paulista/Campus Presidente Prudente \\ medeiroshespanhol@gmail.com
}

\section{Resumo}

As políticas públicas voltadas ao meio rural desempenham papel crucial para a permanência dos produtores no campo. A partir de meados da década de 1990, as políticas públicas voltadas ao espaço rural brasileiro passaram a incorporar a perspectiva territorial, a preocupação ambiental e com a segurança alimentar, bem como a incentivar a participação dos agentes sociais e a organização coletiva dos produtores rurais. O LEADER é um dos marcos da mudança de abordagem (da setorial para a territorial) em termos de políticas públicas implantado na União Europeia a partir dos anos 1990. Os resultados positivos dessa iniciativa comunitária se disseminaram internacionalmente, e contribuiu para que diversos países (inclusive o Brasil) passassem a elaborar políticas de desenvolvimento rural que considerassem a valorização do manejo adequado dos recursos naturais, bem como atendessem os produtores rurais mais carentes. Procurou-se nesse texto, analisar as políticas públicas no Brasil (sobretudo o PAA e o PNAE) e em Portugal (especialmente, a PAC e o LEADER) e a adoção da perspectiva territorial em "detrimento" da setorial.

Palavras-chave: Políticas públicas. Brasil. Portugal. Abordagens setorial e territorial.

\begin{abstract}
Public policies aimed at rural areas play a crucial role in the permanence of producers in the field. From the mid-1990s, public policies aimed at rural Brazil began to incorporate a territorial perspective, the environmental concerns and food security, and to encourage the participation of social partners and collective organization of farmers. The LEADER approach is a change of landmarks (the sector for territorial) in terms of public policies implemented in the European Union from the early 1990. The positive results of this community initiative internationally disseminated, and contributed to several countries (including the Brazil) pass to draw up rural development policies to consider the appreciation of the proper management of natural resources and would meet the poorest farmers. An attempt was made in this text, to analyze public policies in Brazil (especially the PAA and PNAE) and in Portugal (especially, the PAC and LEADER) and the adoption of the territorial prospective "detriment" of the sectorial.
\end{abstract}

CAMPO-TERRITÓRIO: revista de geografia agrária, v. 11, n. 22, p. 185-207, abr., 2016 
Keywords: Public policies. Brazil. Portugal. Sectorial and territorial approaches.

\section{Introdução}

As políticas públicas são medidas muito importantes para a manutenção e viabilização econômica e social dos produtores rurais. O presente texto tem por objetivo apresentar algumas reflexões sobre o papel das políticas públicas para o meio rural brasileiro e português e foi elaborado com base em pesquisa bibliográfica referente, dentre outros temas, ao Programa de Aquisição de Alimentos (PAA), ao Programa Nacional de Alimentação Escolar (PNAE) e ao Programa Ligações Entre Ações do Desenvolvimento da Economia Rural (LEADER).

Procurou-se analisar as políticas públicas no Brasil e em Portugal e a adoção da perspectiva territorial em "detrimento" da setorial. Vale lembrar, segundo Hespanhol, R. (2010a) que, ainda que a abordagem territorial seja importante, ela enfrenta um conjunto de limitações que advém dos seguintes fatores: a) permanência de problemas estruturais, sobretudo a elevada concentração da renda e da propriedade da terra; b) ineficiência das instituições; c) baixa participação da sociedade civil; e, d) persistência de práticas clientelistas.

Hespanhol, A. (2014) salienta que apesar de Portugal e Brasil apresentarem especificidades quanto à dimensão territorial e demográfica e façam parte de contextos geográficos, históricos, econômicos, sociais e políticos distintos, algumas características referentes à agricultura e o mundo rural tiveram reflexos semelhantes em ambos os países. Exemplos disso são os processos de industrialização e de urbanização que se tornaram significativos nos dois países após a II Guerra Mundial e causaram forte deslocamento populacional para as áreas urbanas, sobretudo entre os anos 1960 e 1980 e, a modernização da agricultura que ocorreu de modo seletivo nessas duas realidades.

\section{As políticas públicas para o meio rural brasileiro}

As políticas públicas ${ }^{1}$ implementadas para o rural brasileiro até os anos 1980 partiam dos princípios e concepções que balizaram o Estado brasileiro no período 1920/1980 em que se visava promover o crescimento econômico, por meio da aceleração do processo de industrialização. Em virtude do caráter centralizador do Estado brasileiro, as políticas públicas direcionadas ao meio rural eram setoriais, pois se destinavam, mormente, ao crescimento do volume produzido e dos índices de 
produtividade - decorrentes da incorporação de inovações tecnológicas pelas atividades agropecuárias. Além disso, as políticas públicas eram concebidas sem que houvesse a participação dos pequenos produtores, trabalhadores rurais, dentre outros segmentos que constituem o espaço rural e que foram marginalizados por esse processo (HESPANHOL, R., 2008). Nesse sentido consideramos pertinente uma síntese sobre o processo de modernização da agricultura que se utilizou de políticas públicas e acabou por privilegiar interesses econômicos dominantes e oligarquias rurais e urbanoindustriais envolvidos na agricultura.

\section{O processo de modernização da agricultura no Brasil}

A partir da década de 1960, o governo federal passou a fomentar o processo de modernização da agricultura que visava "melhores níveis de produtividade, via alteração da base técnica (aumento da produtividade do trabalho, da terra e do capital)", que estava calcado na intensificação das relações agricultura-indústria e nas mudanças nas relações sociais (SANTOS, 2004, p. 59).

Modernização essa que, na concepção de Moro (2000), que pesquisou sobre esse processo na agricultura paranaense:

[...] era considerada parcial, conservadora e dolorosa. Parcial porque limitouse a alguns produtos específicos e a certas fases da organização da produção. Conservadora porque não rompeu com a tradicional concentração fundiária, isto é, da posse da terra. Dolorosa porque concorreu para expoliar no campo milhares de pessoas ligadas às atividades agropecuárias, acentuando o êxodo rural e a miséria (MORO, 2000, p. 27).

Kageyama (1987) ao enfocar o padrão agrícola brasileiro explica que essa seleção espacial e setorial da modernização agrícola é evidenciada pelo privilegiamento de apenas alguns produtores (grandes proprietários), determinados produtos (sobretudo, aqueles direcionados à exportação) e regiões, principalmente, a Sudeste e Sul.

Nessa perspectiva, Silva (1998) ao estudar a dinâmica da agricultura brasileira lembra que a modernização agrícola foi deficiente nas regiões Nordeste e Norte, pois estas regiões não conseguiram elevar os níveis de produtividade e acabaram por intensificar ainda mais as disparidades regionais.

De acordo com Delgado (2001), ao analisar a expansão do setor agropecuário no período pós-guerra, a característica de heterogeneidade técnica, social e regional da 
agricultura brasileira foi preservada e até mesmo aprofundada nesse processo de modernização. Sob certo aspecto, pode-se verificar um acordo entre as classes dominantes visando ao processo de modernização da agricultura que direcionou aos latifúndios vários programas, projetos especiais e linhas de apoio, bem como defesa na nova estrutura fiscal e financeira do setor rural.

A modernização da agricultura foi fundamentada na Revolução Verde ${ }^{2}$, que teve como base de apoio o discurso de solucionar o problema da fome mundial, considerando que, para se aumentar a produtividade dos alimentos nos países emergentes, era necessária a adoção de técnicas e insumos modernos na agricultura (JORGE, 2013).

O Estado, por sua vez, através do Sistema Nacional de Crédito Rural (SNCR), financiou o processo de modernização e industrialização da agricultura brasileira. Kageyama (1987) afirma que a política de crédito agrícola no Brasil teve dois momentos: o primeiro, denominado de modernização compulsória, que vigorou de 1965 a 1979, quando o Estado implantou o padrão de modernização para a agricultura através do subsídio direto ao consumo de alguns insumos. No segundo momento, que vai de 1979 a 1986, o Estado restringiu o crédito e deu ênfase na garantia de preços mínimos.

O processo de tecnificação da agricultura - também chamado dessa forma em virtude da significativa incorporação de técnicas - fortemente subsidiado pelo Estado brasileiro culminou no estreitamento das relações entre agricultura e indústria, com significativa subordinação da primeira em relação à segunda, refletindo-se no que se passou a denominar de complexo agroindustrial (CAI), como salienta Delgado (1985).

Sorj (1986, p. 35) ressalta que [...] "o surgimento do complexo agroindustrial no Brasil se dá realmente com a implantação da indústria de maquinaria e insumos agrícolas, por volta do começo dos anos 1960, com o início da produção de tratores”.

A partir desse período, a agricultura brasileira tornou-se "uma estrutura complexa, heterogênea e multideterminada" (SILVA, 1998, p. 5-6) que, por meio dos CAIs, com suas especificidades e dinâmicas referentes aos setores industriais, fornecem insumos e processam matérias-primas agrícolas.

Araújo (2001, p. 30) afirma que a modernização da agricultura no Brasil se deu por meio da "maior abertura ao comércio exterior, expansão dos programas de crédito 
subsidiado e aumento nos gastos em extensão rural, sobressaindo a função do Estado como patrocinador, financiador e regulador da política agrícola".

Cumpre lembrar, de acordo com Silva (2014), que pesquisou a produção do espaço e a reestruturação produtiva do setor de laticínios no Rio Grande do Norte, que a atuação do Estado não se limitou à formulação de políticas de créditos, mas também se estendeu à criação de um aparato institucional para a difusão desse modelo de agricultura moderna, por meio da criação de agências de pesquisa e extensão agropecuária, tais como a Empresa Brasileira de Pesquisa Agropecuária (EMBRAPA) e a Empresa Brasileira de Assistência Técnica e Extensão Rural (EMATER), nos anos 1973 e 1974, respectivamente.

Mudança de abordagem das políticas públicas para o campo no Brasil: os casos do Programa de Aquisição de Alimentos (PAA) e do Programa Nacional de Alimentação Escolar (PNAE)

O caráter centralizador do Estado foi alterado em decorrência de uma nova conjuntura política e social fomentada pelo processo de redemocratização do país - que favoreceu a intensificação de movimentos organizados na sociedade, reivindicando a sua participação. Economicamente falando, citam-se o aprofundamento da crise financeira do Estado brasileiro na década de 1980 e a adoção do modelo neoliberal a partir do início da década de 1990. Com o processo de descentralização político-administrativo, propiciado pela Constituição de 1988, temas como poder local, participação social, autogestão, desenvolvimento sustentável, representação e formas de organização coletiva ganharam relevância em escala nacional (HESPANHOL, R., 2008).

A partir de meados da década de 1990, as políticas voltadas para o espaço rural brasileiro, concebidas pelo Ministério do Desenvolvimento Agrário (MDA), passaram a ter uma perspectiva diferenciada, por meio de mudanças na sua concepção, estruturação e formas de implementação, dando-se ênfase ao enfoque territorial ao invés do setorial, como ocorria até então. Coaduna-se a isso o fato de que, passou-se também a considerar o município como a instância adequada para a execução, a gestão e a fiscalização das políticas públicas (HESPANHOL, R., 2008).

A mudança na lógica das políticas públicas voltadas ao espaço rural foi resultante de um novo cenário internacional e nacional. De acordo com Hespanhol, R. (2008, p. 2), na escala internacional: 
(...) destacou-se a forte influência das políticas europeias que passaram a valorizar o local como referência territorial. Essa valorização do local ocorreu, por um lado, em virtude da grave crise do modelo agrícola produtivista vigente na Europa - que resultou nas reformas da Política Agrícola Comum de 1992 e 1996 - e, por outro, o próprio questionamento da ideia de unilinearidade do processo de desenvolvimento, no qual as diferenças regionais antes vistas como negativas e que teriam de ser eliminadas, passaram a ser reconhecidas como características positivas a serem preservadas e valorizadas. (...) outra mudança fundamental se processou nas agências de apoio à cooperação, fundos de financiamento e organismos multilaterais, como o Fundo Monetário Internacional (FMI), o Banco Mundial, o Banco Interamericano de Desenvolvimento (BID), entre outros, que, sob a forma de orientações, passaram a incorporar em seus programas, a perspectiva do desenvolvimento territorial como forma alternativa de competitividade (...).

Enquanto que na escala nacional:

(...) a perspectiva do desenvolvimento local emerge em decorrência da conjunção de vários fatores, tais como: a) a crise financeira que atinge o Estado brasileiro a partir dos anos 1980; b) a consequente descentralização da administração pública ensejada pela Constituição Federal de 1988 que repassou aos governos municipais competências e atribuições antes delegadas às esferas estadual e federal; e, c) a expansão de Organizações NãoGovernamentais (ONGs), que têm como estratégia de atuação o âmbito local em contraposição aos impactos dos processos globalizantes (HESPANHOL, R., 2008, p. 2).

Uma das primeiras alterações no âmbito do rural foi a implantação do Programa Nacional de Fortalecimento da Agricultura Familiar (PRONAF) ${ }^{3}$ em 1996. A partir da criação dessa política, a agricultura familiar ${ }^{4}$ obteve, pelo menos no discurso oficial, o reconhecimento político e institucional do Estado brasileiro. Desse modo, os "pequenos agricultores", passaram a serem denominados de "agricultores familiares" e tornaram-se público-alvo das políticas públicas no Brasil (GRISA, 2012).

Posteriormente ao PRONAF foram sendo elaboradas outras políticas públicas importantes para o meio rural, como por exemplo, o Programa de Aquisição de Alimentos (PAA) e a reestruturação do Programa Nacional de Alimentação Escolar (PNAE).

O PAA ${ }^{5}$ foi implementado como um programa social que tem se mostrado um importante instrumento de apoio à comercialização da produção agropecuária dos agricultores familiares no Brasil. Esse programa tem sido responsável pela geração de renda, incentivo e apoio aos agricultores que produzem gêneros alimentícios de acordo com os hábitos alimentares locais e regionais. Além disso, tem fomentado formas coletivas de organização (VELOSO, 2011). 
Ainda que o PAA seja uma política pública recente, alguns estudos de caso realizados em diferentes regiões do Brasil mostram que o referido programa tem apresentado resultados positivos, mesmo apresentando certas dificuldades (VELOSO, 2011; HESPANHOL, R., 2010b, dentre outros). De acordo com as especificidades de cada recorte espacial do Brasil, o PAA apresenta características próprias, como discorrem os autores mencionados.

De modo geral, no tocante aos aspectos positivos destacam-se: i) garantia de uma melhor remuneração ao produtor pelos produtos entregues; ii) incentivo à diversificação produtiva e a produção de gêneros alimentícios para o atendimento do consumo familiar e a demanda do mercado local; iii) fomento e/ou aprimoramento dos circuitos locais e regionais de abastecimento e de comercialização; iv) acesso a produtos diversificados e com qualidade pelas entidades assistenciais, com custos mais acessíveis para sua aquisição; v) apoio e fortalecimento das organizações coletivas dos produtores rurais por meio das associações; e vi) valorização dos produtos agroecológicos.

No que tange aos aspectos dificultadores e/ou limitadores do referido programa, os autores supracitados ressaltam: i) privilegiamento dos produtores com melhor condição socioeconômica; ii) problemas na gestão do programa; iii) dificuldade entre os produtores para a elaboração das propostas (no que se refere ao cadastramento dos produtos, produtores e entidades) e na prestação de contas, iv) ausência de assistência técnica para organização, planejamento e produção segundo os padrões de qualidade exigidos pelo programa; v) pequeno número de produtores inseridos no PAA em determinados municípios ${ }^{6}$.

O PNAE, por sua vez, segundo Villar et al. (2013), é uma das políticas públicas mais antigas do país e um dos maiores programas de alimentação escolar do mundo, tanto no que diz respeito ao número de pessoas beneficiadas, quanto no que se refere aos recursos alocados, constituindo-se como uma relevante estratégia de Segurança Alimentar e Nutricional (SAN), ao fomentar o Direito Humano à Alimentação Adequada (DHAA) por meio da alimentação escolar, bem como de várias medidas que auxiliam no alcance das metas dos "Objetivos de Desenvolvimento do Milênio" (ODM). No decorrer de sua implementação, o PNAE passou por várias mudanças que resultaram em avanços, dos quais se destacam o apoio ao desenvolvimento local 
sustentável, com incentivos para a aquisição de gêneros alimentícios diversificados, produzidos em âmbito local, e o respeito aos hábitos alimentares saudáveis e regionais.

Segundo o Ministério do Desenvolvimento Social e Combate à Fome - MDS (BRASIL, 2013), do total de recursos direcionados pelo Fundo Nacional de Desenvolvimento da Educação (FNDE), aos municípios, estados e Distrito Federal, pelo menos $30 \%$ devem ser investidos na compra direta de produtos da agricultura familiar local.

No tocante aos aspectos positivos apresentados pelo PNAE salientam-se: i) o atendimento das necessidades nutricionais dos alunos durante sua estadia na escola, contribuindo para o crescimento, desenvolvimento, aprendizagem e rendimento escolar, e fomentando hábitos alimentares saudáveis; ii) geração de recursos na esfera local em decorrência da entrega dos produtos ao programa; iii) interligação da cadeia alimentar por meio da reaproximação dos elos de produção e consumo que tinham se distanciado em decorrência dos hábitos alimentares que secundarizaram o consumo de legumes, frutas e verduras (BRASIL, 2013; TURPIN, 2008; TRICHES; SCHNEIDER, 2010).

Em relação aos desafios para a implementação do programa citam-se: i) resistência dos produtores para se vincularem às associações; ii) dificuldade dos produtores para a obtenção da Declaração de Aptidão ao PRONAF (DAP) - documento que os habilita a participar desse programa em decorrência da burocracia e da morosidade; iii) sazonalidade e custo da produção; iv) dificuldade para diversificar os produtos a serem entregues; v) dificuldade nas operações e custos logísticos no tocante ao sistema de entrega dos produtos e embalagens; vi) dificuldade de adequação à certificação e ao controle sanitário dos produtos, inclusive dos processados (SILVA; SILVA, 2011; SOUZA, 2012).

\section{As políticas públicas para o meio rural português}

Os espaços rurais em Portugal, assim como no Brasil, foram identificados exclusivamente com as atividades agropecuárias até, pelo menos, meados dos 1980, o que resultou em importantes alterações a partir de 1991, no caso português, com a instituição do Programa LEADER pela União Europeia (HESPANHOL, A. 2014). 
Como já salientado o processo de modernização da agricultura em Portugal foi seletivo, assim como no Brasil, ainda que em proporções diferenciadas. Portanto, acredita-se ser pertinente uma análise desse processo no item seguinte.

\section{O processo de modernização da agricultura em Portugal e a Política Agrícola Comum (PAC)}

A modernização agrícola portuguesa ocorreu entre as décadas de 1960 e 1970 e de modo seletivo em relação aos produtos (cereais, carne bovina, açúcar de beterraba, dentre outros), agricultores (os que mais produziam) e regiões (de um modo geral, ocorreu no sentido Norte/Sul e Litoral/Interior, priorizando as áreas mais desenvolvidas, povoadas e dinâmicas) (CAVACO, 1992).

O expressivo êxodo rural apresentado a partir dos anos 1960 fomentou a modernização da agricultura portuguesa para suprir a redução da mão-de-obra humana (CAVACO, 2006).

Após a adesão de Portugal à União Europeia e com a reforma de 2003 da Política Agrícola Comum (PAC), as políticas públicas voltadas ao desenvolvimento da agricultura e do meio rural foram estruturadas, fundamentalmente, no Plano Estratégico Nacional para o Desenvolvimento Rural (PENDR), que assegura a coerência do apoio comunitário ao desenvolvimento rural com as orientações estratégicas comunitárias, bem como a coordenação de todas as prioridades comunitárias, nacionais e regionais, constituindo o instrumento de referência para a preparação do Programa de Desenvolvimento Rural (PDR). O PDR define as medidas e correspondentes ações e subações do Plano Estratégico Nacional de Desenvolvimento Rural 2007-2013 (MATOS; SANTOS; LOPES, 2008).

Este programa foi apoiado pelo Fundo Europeu Agrícola de Desenvolvimento Rural (FEADER) que, segundo Matos, Santos e Lopes (2008), é um instrumento único de financiamento da política europeia de desenvolvimento rural que objetiva contribuir para aumentar a competitividade dos setores agrícola e florestal, para melhorar o ambiente, a gestão do espaço rural e a qualidade de vida e para diversificar as atividades nas zonas rurais.

De acordo com Matos, Santos e Lopes (2008), o mundo rural português registrou uma perda expressiva das vitalidades demográfica e econômica. Considerando, segundo Cavaco (2006), que o progresso da agricultura em Portugal está 
muito mais atrelado a determinantes externas, sobretudo comunitárias (PAC, por exemplo), do que por determinantes internas (política agrícola nacional) e que esta [PAC] tem influenciado "nos cultivos e nas rotações, nos métodos e nas técnicas, nos arranjos dos campos e aldeias, nas paisagens, nos efectivos animais, nas estruturas familiares, económicas e sociais (...)" (CAVACO, 2006, p. 35), acreditamos ser relevante uma síntese das reformas na PAC.

\section{A PAC: evolução e reformas}

$\mathrm{Na}$ década de 1960, enquanto o setor agrícola português apresentava um baixíssimo dinamismo num cenário de atraso tecnológico, baixas produtividades, difícil condição de vida da população rural e insuficiências alimentares (CAVACO, 2006), verificaram-se grandes alterações em termos europeus com a criação da Comunidade Econômica Europeia $(\mathrm{CEE})^{7}$ e da PAC.

O Tratado de Roma $^{8}$ aponta que os principais objetivos da PAC eram: potencializar a produtividade da agricultura, de modo a garantir um nível de vida equitativo à população agrícola; estabilizar os mercados; e possibilitar a segurança do abastecimento a preços acessíveis ao consumidor. Em decorrência da garantia firmada pela Comunidade Europeia em assumir as medidas necessárias ao funcionamento da PAC, foi necessária a criação de um fundo comum destinado ao financiamento da politica agrícola que também foi prevista no Tratado de Roma. A partir de sua criação em 1962, o Fundo Europeu de Orientação e Garantia Agrícola (FEOGA) ${ }^{9}$ passou a representar a maior verba unitária do orçamento comunitário (COMUNIDADES EUROPEIAS, 1989).

A gestão e a organização comum de mercado, ou seja, a política comum de preços e de mercados representava apenas uma parte da solução para os problemas da agricultura europeia. Assim, a partir de abril de 1972, a PAC passa a priorizar a modernização e a formação dos agricultores. Os objetivos eram: reorganizar as explorações por meio do aumento da superfície agrícola utilizada por exploração, no sentido da sua integração, para obtenção de viabilidade econômica nos métodos modernos da agricultura industrial e, desta forma, possibilitar acréscimos de rendimento e produtividade. Além disso, buscava intervir ao nível dos ativos agrícolas através de medidas relacionadas com a 
formação de agricultores (maximizando o seu empreendedorismo), a reconversão profissional (de agricultores mais novos que quisessem dedicar-se a uma atividade fora do setor agrícola) e a concessão de aposentadorias antecipadas aos agricultores com mais de 55 anos, em áreas propícias para a expansão de empresas. Em síntese, a PAC, a partir de 1972, deveria incentivar os agricultores que quisessem retirar-se da atividade agrícola e liberar suas terras para a expansão de outras empresas, e apoiar estas no seu desenvolvimento (CARVALHO, 2008).

De acordo com Cavaco (2006), de um modo geral, as regiões e as explorações deveriam especializar-se segundo as suas vantagens comparativas e competitivas e serem eficientes; as explorações marginais e as regiões desfavorecidas deveriam ser auxiliadas; e os excedentes de mão-de-obra deveriam ser redirecionados para outras explorações, regiões ou atividades. A implantação desta política, com proteção dos mercados, principalmente de produtos alimentares básicos, que são dominantes na produção dos países da Europa do Norte e estímulos à modernização técnica, ocasionou grande aumento da produção e excedentes, com os respectivos custos da alimentação dos europeus e do escoamento por meio de exportações subsidiadas, mas sem garantia de equidade de rendimento para todos os produtores. Havia, então, uma predileção pelos agricultores que mais produziam, que dispusessem de produtos com preços mais altos, como por exemplo, os cereais, o leite, a carne de bovinos e o açúcar de beterraba e que trabalhavam com maior eficiência.

Segundo Hespanhol, R. (2012), a modernização da agricultura portuguesa causou a geração de problemas nos âmbitos fitossanitário e ambiental, em virtude do uso indiscriminado de máquinas e insumos químicos. Em decorrência desses problemas ambientais, da superprodução agrícola, dos impasses comerciais e do alto custo de manutenção da PAC foram realizadas continuadas reformas nessa política a partir dos anos de 1990 (1992, 1999 e 2003).

A PAC necessitou de uma nova reforma em 1992. De acordo com Barros (2003), essa reforma, fundamentada na necessidade de redução da produção, veio dar notoriedade às políticas de desenvolvimento rural e à necessidade de uma abordagem mais integrada das áreas rurais, mais ajustada ao atraso estrutural de Portugal e às potencialidades que aquele mesmo atraso, determinara, preservando a diversidade das condições físicas e climáticas do país. 
Com a Reforma da PAC, ocorreu uma diminuição dos preços dos cereais, da carne bovina e dos produtos lácteos; o controle direto da produção, em especial por meio do sistema de quotas (de produção, de superfície ou de direito a prêmios); medidas de exceção para as pequenas explorações e medidas de acompanhamento voltadas ao setor ambiental, com vistas à preservação (CUNHA, 2000).

Em suma, essa Reforma instituiu o pagamento direto ao agricultor como medida compensatória da queda nos preços de sustentação, de modo a controlar a oferta de produtos agropecuários e evitar a superprodução. Além dessa medida, a PAC passou a priorizar e valorizar a sustentabilidade ambiental e a reconhecer o caráter multifuncional dos espaços rurais (HESPANHOL, R., 2012).

Nessa perspectiva, Matos, Santos e Lopes (2008) salientam que é necessário ter em vista as potencialidades correlacionadas à multifuncionalidade do espaço rural e a consequente promoção de diversificação do âmbito econômico por meio da criação de competências locais e serviços de apoio e da conservação e valorização do patrimônio cultural $^{10}$ e do patrimônio paisagístico ${ }^{11}$, com a dinamização de um conjunto de outras atividades econômicas, a saber: turismo, artesanato, produção e venda de produtos tradicionais, serviços de transporte, de animação, dentre outras.

De acordo com Baptista (1993), a nova PAC (1992) continuou a privilegiar os produtos mais relevantes do Centro e Norte da Europa em detrimento dos mediterrânicos que representavam numerosos sistemas de produção dos países do Sul. Além disso, passou a agravar a tendência de Portugal se transformar num espaço não produtivo, com dependência alimentar, e, concomitantemente, levou a uma parte da sua população para os mercados de trabalho de outros países da Europa.

Segundo Cavaco (2006), os preços europeus ainda ultrapassavam exorbitantemente os do mercado mundial, e eram geralmente instáveis em decorrência das flutuações monetárias. Diante desta situação, em 1999, foi aprovada a Agenda $2000^{12}$, que reformulou outra vez a PAC, mantendo, no entanto, o modelo de política empreendido pela reforma anterior e, por consequência, acentuando as mudanças então introduzidas, num cenário de compromisso dos limites orçamentais. Vale lembrar que a PAC continuava a absorver quase $50 \%$ do orçamento comunitário. Dentre as medidas desse acordo, as principais são: novas diminuições nos preços institucionais, sobretudo no preço de intervenção nos cereais; reduções parciais no preço indicativo do leite e nos 
preços de intervenção da manteiga e do leite em pó desnatado, e compensações com pagamentos diretos e/ou prêmios por tonelada de quota e suplementares; manutenção de sistemas de quotas, áreas e quantidades máximas de garantia para o leite, o açúcar, o tomate, o trigo duro/rijo, o tabaco, a vinha e os efetivos bovinos e ovinos.

Já no ano de 2003 houve uma reforma intercalar com novas interferências nas culturas de cereais, de oleaginosas, além das incidências no setor de carnes de bovino, ovino e caprino e leite, dentre outros. Ainda assim, o pagamento das ajudas diretas reforçava os compromissos relativos ao ambiente, ao bem-estar animal e à segurança alimentar, correspondentes às novas preocupações dos consumidores (CAVACO, 2006).

Numa visão favorável à Reforma de 2003 da PAC, Barros (2003) enfatiza que, na realidade europeia, a agricultura progrediu, pois embora o agricultor tenha perdido peso econômico enquanto produtor de bens, este ganhou uma significativa importância como prestador de serviços quer em termos de conservação dos recursos naturais, do ambiente e da paisagem, quer no caráter da satisfação de novas necessidades do consumidor ligadas à recreação e ao lazer.

Nessa perspectiva, o autor supracitado afirma ainda que, durante muito tempo os problemas da agricultura eram tratados de modo isolado e depois dessa Reforma o agricultor passou a ser considerado um ator da sociedade e os aspectos social, econômico e técnico passaram a ter dinâmicas específicas, mas de modo inter-relacionado. As questões agrícolas são coordenadas de modo vertical, ou seja, do ponto de vista da produção e do mercado, e horizontal à escala do desenvolvimento local ou regional.

A reforma ocorrida em 2013 alterou quatro regulamentos-base da PAC, a saber: a) pagamentos diretos; b) Organização Comum de Mercado (OMC); c) Desenvolvimento Rural; e d) Regulação Horizontal do Financiamento, da Gestão e do Acompanhamento da PAC. De acordo com o relatório do Centro de Estudos de Gestão e Economia Aplicada (CEGEA), publicado em 2012, a reforma da PAC de 2013 tem como objetivos: reforçar a competitividade por meio de melhores instrumentos de mercado, novos mecanismos de gestão de risco e apoio à investigação e inovação; melhoria da sustentabilidade, com foco nas questões ambientais, bem como a reestruturação das ajudas e simplificação da política vigente.

A reforma supracitada ocorreu por meio da implementação do Tratado de Lisboa (protagonismo do Parlamento Europeu) para o período de 2014-2020. No que se refere ao 
discurso dominante salientam-se: a redução do orçamento da PAC, aposta na diversidade agrícola e rural da União Europeia, coexistência entre enfoques setoriais e territoriais, interação rural-urbana, uma PAC territorial e ambientalista (luta contra as mudanças climáticas) e coesão social-econômica dos territórios rurais. Quanto aos mercados agrícolas e os instrumentos e mecanismos de atuação citam-se: o pagamento único por exploração e pagamentos complementares, reforma do sistema de pagamentos diretos (eliminação dos "direitos históricos"), convergência interna e externa dos pagamentos, definição de "agricultor ativo" como preceptor das ajudas diretas, introdução do "greening"13 obrigatório, dentre outros (MOYANO-ESTRADA; ORTEGA, 2014).

Os autores supramencionados afirmam que no tocante às estruturas agrárias e o desenvolvimento rural (quanto às medidas e aos programas) frisam-se: a modificação do Regulamento de Desenvolvimento Rural, a diferenciação entre o desenvolvimento ruralagrário e o desenvolvimento rural-territorial, o início da separação entre a política agrária e a política rural. Além disso, a política rural pode ser financiada com os demais fundos estruturais. Quanto aos fundos econômicos ressalta-se que, são mantidos oFundo Europeu de Orientação e Garantia Agrícola (FEOGA) e o Fundo Europeu Agrícola de Desenvolvimento Rural (FEADER), mas se possibilita que o desenvolvimento rural seja financiado a partir de multi-fundos.

Moyano-Estrada e Ortega (2014) afirmam que, no tocante à participação das comunidades locais, verifica-se uma nova forma de entender a governança. Mesmo tomando como base o enfoque ascendente e participativo que rendeu bons resultados na iniciativa LEADER, a nova programação maximiza o horizonte da governança aos setores econômicos, sociais, culturais e institucionais presentes nos territórios (estratégia de Desenvolvimento Local gerido pelas Comunidades Locais - DLCL), garantindo sua presença nos novos "grupos de ação local" e firmando sua participação real e efetiva no processo de tomada de decisões. Em analogia com a iniciativa LEADER, pode-se prever a superação da perspectiva dicotômica rural-urbana. O rural passa a ser parte de uma estratégia mais abrangente de desenvolvimento com a nova PAC e a política de coesão agindo em conjunto. Os recursos devem ser direcionados, no caso do segundo pilar da PAC, às ações de desenvolvimento local/territorial (rural, urbano, pesqueiro e litorâneo). 
Mudança de abordagem das políticas públicas para o campo em Portugal: o caso do Programa Ligações Entre Ações do Desenvolvimento da Economia Rural (LEADER)

Um dos marcos da mudança de abordagem em termos de políticas públicas foi o Programa Ligações Entre Ações do Desenvolvimento da Economia Rural (LEADER) implantado na União Europeia a partir dos anos 1990. Esse programa inovou ao considerar as especificidades locais das regiões selecionadas com a utilização do enfoque territorial em substituição ao setorial (HESPANHOL, R., 2010a).

O LEADER passa a considerar novas perspectivas de desenvolvimento além daquela calcada exclusivamente na agricultura, ou seja, passa a valorizar a multifuncionalidade do espaço rural, dentre outros aspectos.

O referido programa é dividido em três fases, a saber: LEADER I (1991-1994), LEADER II (1995-1999) e LEADER+ (2000-2006). A extensão do LEADER resultou no aumento do número de projetos direcionados ao programa em Portugal e em sua cobertura territorial, em virtude do território português ser constituído de áreas consideradas prioritárias desse programa, ou seja, territórios rurais deprimidos, caracterizados pelo êxodo de jovens, envelhecimento da população, atraso tecnológico e baixa produtividade da agricultura, dentre outros aspectos (SARON; JACINTO; HESPANHOL, A., 2014).

Embasados em Favareto (2007), Neves Neto e Hespanhol, A. (2014, p. 80) afirmam que:

\footnotetext{
As primeiras edições do programa se diferenciaram pelo caráter territorial apresentado, em oposição aos programas setoriais; pelo envolvimento do número de participantes na elaboração, execução e fiscalização dos projetos; na integração de várias políticas públicas, na articulação de membros diversos da sociedade - instituições, empresas, organizações nãogovernamentais - e no estímulo a criatividade e à valorização dos conhecimentos locais (FAVARETO, 2007).
}

Os autores supracitados afirmam ainda que as três edições do Programa LEADER demostraram que o desenvolvimento rural só pode ser obtido se houver um planejamento eficiente de execução de projetos e a participação dos atores e instituições envolvidas, por meio de ações multissetoriais e integradas. As referidas ações são denominadas bottom-up, ou seja, de baixo para cima, por envolver os atores locais na execução dos projetos e se diferem das anteriores top-down (de cima para baixo). 
De acordo com Neves Neto (2013), os resultados positivos dessa iniciativa comunitária, na União Europeia, se disseminaram internacionalmente, e diversos países passaram a elaborar políticas de desenvolvimento rural que considerassem a opinião dos participantes e a valorização do manejo adequado dos recursos naturais, bem como atendessem os produtores rurais mais carentes.

Os projetos do LEADER em Portugal abordavam ações variadas, na agricultura os projetos objetivavam a agregação de valor a produtos típicos (queijos, vinhos, dentre outros); a preservação e exploração do patrimônio natural, histórico, cultural com finalidades turísticas, e; obras de infraestrutura direcionadas para o bem estar da população rural, dentre outras (SARON, 2014).

Mesmo considerando os resultados alcançados em Portugal, o LEADER não beneficiou a parcela da população que vive no rural "profundo", que são áreas pobres situadas principalmente no interior. Desse modo, os grupos de agricultores que não são organizados em associações, não são inseridos no mercado, com perfis menos empreendedores, ficaram à margem do LEADER (ROVER; HENRIQUES, 2006 apud NEVES NETO, 2013).

\section{Considerações finais}

O propósito do presente texto não foi esgotar as temáticas abordadas, mas traçar uma análise comparativa sobre algumas políticas públicas brasileiras e portuguesas sob as perspectivas setorial e territorial, levando em conta desde a modernização da agricultura até a implantação do Programa de Aquisição de Alimentos (PAA) e do Programa Nacional de Alimentação Escolar (PNAE) no Brasil e do Programa Ligações Entre Ações do Desenvolvimento da Economia Rural (LEADER) em Portugal.

Verificou-se que, mesmo considerando as diferenças territoriais e demográficas entre Brasil e Portugal, esses países apresentam semelhanças significativas. Tanto num país como no outro, a modernização da agricultura foi seletiva. Além disso, as políticas públicas em ambos os países foram alteradas após a década de 1990 partindo da perspectiva setorial para a territorial.

No Quadro 1 tem-se a síntese das políticas públicas voltadas ao meio rural no Brasil e em Portugal. 
Quadro 1: Síntese das políticas públicas voltadas ao meio rural no Brasil e em Portugal a partir da década de 1990

\begin{tabular}{|c|c|c|c|c|c|}
\hline País & Programas & $\begin{array}{l}\text { Ano de } \\
\text { criação }\end{array}$ & Abordagem & $\begin{array}{c}\text { Semelhanças entre } \\
\text { os programas } \\
\text { estudados no } \\
\text { Brasil e em } \\
\text { Portugal } \\
\end{array}$ & $\begin{array}{c}\text { Diferenças entre } \\
\text { os programas } \\
\text { estudados no } \\
\text { Brasil e em } \\
\text { Portugal } \\
\end{array}$ \\
\hline & PAA & 2003 & errit & \multirow{4}{*}{$\begin{array}{c}\text { Criação dos } \\
\text { programas a partir } \\
\text { da década de 1990; } \\
\text { Os programas } \\
\text { buscam o } \\
\text { desenvolvimento } \\
\text { rural. }\end{array}$} & \multirow{4}{*}{$\begin{array}{c}\text { Disseminação do } \\
\text { apoio às atividades } \\
\text { não agrícolas no } \\
\text { caso português ao } \\
\text { contrário do caso } \\
\text { brasileiro, ou seja, } \\
\text { em Portugal por } \\
\text { meio dos referidos } \\
\text { programas houve o } \\
\text { incentivo a } \\
\text { multifuncionalidade } \\
\text { do espaco rural. }\end{array}$} \\
\hline Brasil & PNAE & $\begin{array}{c}1950 \\
\text { reformulado } \\
\text { em } 2009\end{array}$ & Territorial & & \\
\hline \multirow{2}{*}{ Portugal } & $\begin{array}{l}\text { LEADER I, } \\
\text { LEADER II e } \\
\text { LEADER+ } \\
(2000-2006) .\end{array}$ & $\begin{array}{l}1991-1994 \\
1995-1999 \\
2000-2006\end{array}$ & Territorial & & \\
\hline & PRODER & 2007 & Territorial & & \\
\hline
\end{tabular}

Fonte: Adaptado de Saron (2014); Hespanhol R. (2010a).

De acordo com Saron (2014), em relação ao caso brasileiro, não há uma classificação do PAA enquanto programa fundamentado na abordagem territorial, nem mesmo nos documentos oficiais. No entanto, o seu funcionamento confere algumas características de uma política territorial, ainda que não seja plena, já que, articula o campo e a cidade, com agricultores interessados em vender a produção e citadinos em terem acesso aos produtos agrícolas, requer a mobilização e organização social em torno de organizações coletivas como associações e cooperativas e também dos beneficiários dos alimentos, contempla ações de incentivo ao desenvolvimento econômico e a segurança alimentar, dentre outros aspectos.

Ainda de acordo com o autor supracitado, alguns aspectos que fazem considerar o PAA como um programa pautado na abordagem territorial são válidos para o Programa Nacional de Alimentação Escolar (PNAE). Cumpre lembrar que as principais diferenças dizem respeito ao direcionamento mais especifico do PNAE (agricultores e escolas), envolvendo assim uma rede de sujeitos e atores sociais menos articulada na escala local se comparada ao PAA, e não requerer a mobilização acerca de organizações coletivas (o PAA com exceção de algumas de suas modalidades demanda a organização dos agricultores). Além disso, há no PNAE uma maior exigência na regularidade e no padrão de qualidade em contratos firmados por meio das chamadas públicas.

Ao se tratar do Brasil, em consonância com Hespanhol, R. (2010a), acreditamos que, no que se refere à participação representativa dos principais atores sociais nas 
escalas local/regional e do alcance dessas políticas, muito ainda há para se modificar, se considerarmos algumas limitações e problemas identificados nos municípios, como por exemplo, paternalismo, coronelismo, dentre outros. Cumpre lembrar que, enquanto persistirem os problemas estruturais no país, como a concentração fundiária e de renda, dificilmente as políticas públicas serão capazes, de isoladamente, reverter o quadro socioeconômico brasileiro, sobretudo nos espaços rurais e no tocante aos segmentos sociais mais carentes.

Ainda assim, verificou-se que mesmo com todas as limitações apresentadas pelo PAA e pelo PNAE, por exemplo, essas políticas públicas têm se mostrado importantes para a permanência dos produtores no campo e contribuído para a resolução de um dos maiores gargalos da produção: a comercialização, dentre outros resultados positivos.

Enquanto que no caso português, o Programa de Desenvolvimento Rural (PRODER) foi oficialmente criado em 2007, em conformidade com as orientações estabelecidas pelo FEADER para a criação de programas nacionais de desenvolvimento rural. O programa une as medidas e ações que estavam dicotomizadas nos Quadros Comunitários de Apoio (QCA) I, II e III nos Programas Operacionais da Agricultura e Desenvolvimento Rural e no LEADER. Assim, contempla o apoio à agricultura e também o desenvolvimento rural num único programa. O referido programa é dividido em quatro subprogramas, a saber: 1) Promoção da competitividade, 2) Gestão sustentável do espaço rural, 3) Dinamização das zonas rurais e 4) Promoção do conhecimento e desenvolvimento de competências (SARON, 2014).

A PAC que antes apresentava uma abordagem setorial, a partir da reforma de 2013 (para o período de 2014-2020), passa a ter a coexistência entre as perspectivas setorial e territorial.

Por fim, o LEADER é um dos marcos da mudança de abordagem (da setorial para a territorial) em termos de políticas públicas implantado na União Europeia a partir dos anos 1990. Os resultados positivos dessa iniciativa comunitária se disseminaram internacionalmente, e contribuíram para que diversos países passassem a elaborar políticas de desenvolvimento rural que considerassem a valorização do manejo adequado dos recursos naturais, bem como atendessem os produtores rurais mais carentes. 


\section{Notas}

${ }^{1}$ A temática Políticas públicas é de grande relevância para a Geografia e se refere, dentre outras definições, às decisões voltadas às questões de ordem pública com abordagem ampla e que objetivam à satisfação do interesse de uma coletividade. Podem também ser entendidas como estratégias de atuação pública, estruturadas por meio de um processo decisório que reflete na realidade (AMABILE, 2012).

${ }^{2}$ De acordo com Brum (1983), ao analisar a modernização da agricultura no Planalto Gaúcho, a "Revolução Verde" se consolidou como um mecanismo para maximizar, mundialmente, a venda de insumos agrícolas modernos: máquinas, equipamentos, implementos fertilizantes, defensivos, pesticidas, dentre outros. $\mathrm{Na}$ concepção do autor, esta foi uma maneira que os grupos econômicos internacionais encontraram para a expansão de suas empresas e de seus interesses com rapidez e eficiência.

${ }^{3}$ De acordo com Hespanhol, R. (2000), o PRONAF foi regulamentado pelo Decreto $\mathrm{n}^{\circ}$. 1.946 de 28/06/1996 pelo governo federal. Esse programa tem como objetivo a promoção do desenvolvimento sustentável do segmento rural formado por agricultores familiares, propiciando assim, o aumento da capacidade produtiva, a geração de emprego e a melhoria da renda.

${ }^{4} \mathrm{~A}$ agricultura familiar é uma forma de produção em que as decisões, gerência, trabalho e capital são de responsabilidade da família e têm como fatores relevantes além da família, do trabalho e da produção, as tradições culturais. Concomitantemente são assumidas as funções de proprietário e de trabalhador no estabelecimento rural (MENEZES; MARTINES; PAGANI NETTO, 2012).

${ }^{5}$ O PAA foi instituído pelo artigo 19 da lei $\mathrm{n}^{\mathrm{o}}$. 10.696, de 10 de julho de 2003, e regulamentado pelo Decreto $n^{\circ}$. 6.447, de 07 de maio de 2008 (VELOSO, 2011).

${ }^{6}$ Como exemplo, podemos citar os municípios de Dracena, Junqueirópolis e Tupi Paulista pertencentes à Microrregião Geográfica de Dracena, segundo Hespanhol, R. (2010b).

${ }^{7} \mathrm{CEE}$ é o nome da organização internacional que surgiu em 1958, com o Tratado de Roma. No entanto, para sua criação foi fundamental o Tratado de Paris de 1951 que criava a Comunidade Europeia do Carvão e do Aço (CECA), que contava exatamente com os mesmos membros que se reuniriam em Roma posteriormente: Alemanha Ocidental, França, Itália, Bélgica, Países Baixos e Luxemburgo. Mais tarde, em 1965, o Tratado de Bruxelas iria fundir a CECA, a Comunidade Europeia de Energia Atômica (EAEC ou Euratom) e a CEE em um só organismo denominado "Comunidades Europeias". A comunidade, que contava inicialmente com seis membros, teve a adesão em 1973 de Irlanda, Reino Unido e Dinamarca. Mais tarde, em 1981, foi a vez da Grécia, e em 1986, de Portugal e Espanha. Sucessivos alargamentos fizeram com que, atualmente esta instituição seja constituída por 27 estados. A partir de 1993 com o Tratado de Maastricht, a CEE é substituída pela União Europeia (Disponível em: União Europeia. Agricultura. < http://europa.eu/index_pt.htm>).

8 "O Tratado de Roma foi um acordo assinado em 25 de março de 1957, em Roma, tendo como objectivo eliminar as barreiras comerciais entre os Estados-membros e criar um mercado comum onde circulassem livremente os indivíduos, as mercadorias e os capitais" (MATOS; SANTOS; LOPES, 2008, p. 208).

${ }^{9}$ O FEOGA abrange dois domínios. A Secção Garantia financia as despesas comunitárias originadas pela politica de preços e de mercados, enquanto a Secção Orientação disponibiliza meios financeiros para a política comum das estruturas agrícolas. Na sua grande maioria, a ação do FEOGA incide sobre as despesas de garantia agrícola.

10"Patrimônio cultural: conjunto de bens e saberes que constituem a riqueza de um povo, inclui por isso todos os vestígios de actividade humana no ambiente físico" (MATOS; SANTOS; LOPES, 2008, p. 45).

11 "Patrimônio paisagístico: conjunto dos diferentes elementos da paisagem (físicos, humanos, biológicos, culturais...) que interagem formando conjuntos únicos e indissociáveis, em contínua evolução" (MATOS; SANTOS; LOPES, 2008, p. 45).

${ }^{12}$ Agenda 2000: programa de ação cujos principais objetivos consistiram em reforçar as políticas comunitárias e dotar a União Europeia de um novo quadro financeiro para o período de 2000-2006 (...). Este programa de ação foi concretizado em 1999 mediante cerca de vinte textos legislativos que diziam respeito à prossecução das reformas agrícolas, à eficácia acrescida dos fundos estruturais e ao reforço da estratégia de pré-adesão dos países candidatos (MATOS; SANTOS; LOPES, 2008, p. 38).

${ }^{13} \mathrm{O}$ "greening" prevê a remuneração dos agricultores que introduzam, obrigatoriamente, práticas agrícolas que objetivem evitar a deterioração dos recursos naturais (por exemplo, a erosão dos solos), ainda que isso represente uma diminuição da produtividade a curto prazo das explorações (MOYANOESTRADA; ORTEGA, 2014). 


\section{Referências}

AMABILE, A. E. N. Políticas públicas. In: CASTRO, C. L. F.; GONTIJO, C. R. B.; AMABILE, A. E. N. (Org.). Dicionário de políticas públicas. Barbacena: EdUEMG, 2012.

ARAÚJO, I. M. Agroindustrialização e diversificação das atividades agropecuárias: o caso do município de São Gabriel do Oeste - MS. 183 f. Dissertação (Mestrado em Geografia) - Faculdade de Ciências e Tecnologia, Universidade Estadual Paulista, Presidente Prudente, 2001.

BAPTISTA, F. O. Agricultura, Espaço e Sociedade Rural. Coimbra: Fora do Texto, 1993.

BARROS, V. C. Desenvolvimento rural: intervenção pública, 1996-2002. Lisboa: Terramar, 2003.

BRASIL. Ministério do Desenvolvimento Social e Combate à Fome (MDS). Plano Brasil sem miséria no seu município, Brasília, 2013. Disponível em: $<$ http://www.mds.gov.br/brasilsemmiseria/arquivos/Cartilha_BSM,P20eleitoral_Munici pio_20x25cm_10072014.pdf.pagespeed.ce.ioh8sxhan-.pdf>. Acesso em: 15 set. 2014.

BRUM, A. J. Modernização da agricultura no Planalto Gaúcho. Ijuí: FIDENE, 1983.

CARVALHO, P. União Europeia, políticas públicas e desenvolvimento rural. In: Cadernos de Geografia, Coimbra, n. 26/27, p. 67-76, 2007/2008.

CAVACO, C. Portugal Rural: da tradição ao moderno. $1^{\text {a }}$ ed. Lisboa, Portugal: Ministério da Agricultura, 1992.

CAVACO, C. Enquadramento macroeconômico: mudanças e crise. In: MEDEIROS, C. A. (Org.). Geografia de Portugal: atividades econômicas e espaço geográfico. Vol. 3. Lisboa: Círculo de leitores, 2006, p. 34-45.

CENTRO DE ESTUDOS DE GESTÃO E ECONOMIA APLICADA (CEGEA). Impacto da reforma da PAC pós-2013 no setor do leite em Portugal: Relatório 2012. Disponível em:<

http://www.confagri.pt/SiteCollectionDocuments/Confagri/Associadas/Fenalac_versaof inal_6\%20de\%20Julho\%20de\%202012.pdf >. Acesso em: 25 jul. 2013.

CLEMENTE, E. C. Formação, dinâmica e a reestruturação da cadeia produtiva do leite na região de Jales - SP. 196 f. Dissertação (Mestrado em Geografia) - Faculdade de Ciências e Tecnologia, Universidade Estadual Paulista, Presidente Prudente, 2006.

COMUNIDADES EUROPEIAS. Uma Politica Agrícola Comum para os anos noventa. 3. ed. Luxemburgo: Serviço das Publicações Oficiais das Comunidades Europeias, 1989. 
CUNHA, A. A Política Agrícola Comum e o futuro do mundo rural. Lisboa: Plátano Edições Técnicas, 2000.

DELGADO. G. C. Expansão e modernização do setor agropecuário no pós-guerra: um estudo da reflexão agrária. In: Estudos Avançados, v. 15, n. 43, p. 157-172, 2001.

GRISA, C. Políticas públicas para a agricultura familiar no Brasil: a produção e institucionalização das ideias. $280 \mathrm{f}$. Tese (Doutorado em Ciências). Instituto de Ciências Humanas, Universidade Federal Rural do Rio de Janeiro, Rio de Janeiro, 2012.

HESPANHOL, R. A. M. Produção familiar: Perspectiva de análise e inserção na Microrregião Geográfica de Presidente Prudente - SP. 354 f. Tese (Doutorado em Geografia). Instituto de Geociências Exatas, Universidade Estadual Paulista, 2000.

HESPANHOL, A. N. Abordagem territorial e fomento ao desenvolvimento rural no Brasil e em Portugal. In: XXII ENCONTRO NACIONAL DE GEOGRAFIA AGRÁRIA- ENGA: Agentes, processos, conflitos e conteúdos do espaço agrário brasileiro. Anais...Natal-RN: nov. 2014, p. 424-437.

HESPANHOL, R. A. M. Mudança de concepção das políticas públicas para o campo brasileiro: o Programa de Aquisição de Alimentos (PAA). Scripta Nova: Revista Electrónica de Geografia y Ciencias Sociales. Barcelona: Universidad de Barcelona, 1 ago. 2008, vol. II, no 270 (79). Disponível em: <.http://www.ub.es/geocrit/xcol/221.htm>. Acesso em: 19 mar. 2015.

HESPANHOL, R. A. M. A adoção da perspectiva territorial nas políticas de desenvolvimento rural no Brasil. Campo-território: revista de geografia agrária, v. 5, n. 10, ago. 2010a, p. 125-147. Disponível em: < http://www.seer.ufu.br/index.php/campoterritorio/article/view/11964/8247>. Acesso em: 12 ago. 2015.

HESPANHOL, R. A. M. Políticas públicas e estratégias coletivas de comercialização agrícola. In: CUNHA, L.; PASSOS, M. M.; JACINTO, R. (Coord.). As novas geografias dos países de língua portuguesa: paisagens, territórios, políticas no Brasil e em Portugal. Guarda: Centro de Estudos Ibéricos, p. 393-410, 2010b (Coleção Iberografias, v. 10).

HESPANHOL, R. A. M. Espaços rurais, povoamento e processos migratórios em Portugal e no Brasil. In: MODESTO, M. M.; CUNHA, L.; JACINTO, R. (Org.). As novas Geografias dos Países de Língua Portuguesa: Paisagens, Territórios e Politicas públicas no Brasil e em Portugal. São Paulo: Outras Expressões, 2012. p. 171-188.

JORGE, A. A. Do café para a pastagem: o processo e os desdobramentos da modernização agrícola no município de Cruzeiro do Sul - Paraná. In: VI SIMPÓSIO INTERNACIONAL DE GEOGRAFIA AGRÁRIA, VII SIMPÓSIO NACIONAL DE GEOGRAFIA AGRÁRIA E I JORNADA DE GEOGRAFIA DAS ÁGUAS. Anais... João Pessoa-PB: UFPB, 2013. 
KAGEYAMA, A. A. (Coord.). O novo padrão agrícola brasileiro: do complexo rural aos complexos agroindustriais. Campinas, 1987.

MATOS, A.; SANTOS, F.; LOPES, F. Espaço português. Lisboa: Asa Edições, 2008.

MENEZES, C. C. P.; MARTINES, L.; PAGANI NETTO, C. Projeto CATI Leite. In: PAGANI NETTO, C. (Coord.). Manual técnico CATI. Campinas, n. 80, dez. 2012, p. $1-12$.

MOYANO-ESTRADA, E. M.; ORTEGA, A. C. A reforma da PAC para o período 2014-2020: uma aposta no desenvolvimento territorial. Revista de Economia e Sociologia Rural, Rio de Janeiro, v. 18, n.4, oct./dez. 2014.

MORO, D. A. A modernização da agricultura paranaense. In: VILLALOBOS, J. U. G. (Org.). Geografia social e agricultura. Maringá: Programa de Pós-Graduação em Geografia - UEM, 2000.

NEVES NETO, C. C. Políticas públicas e desenvolvimento rural: o Programa de Microbacias I e II no Estado de São Paulo. 313. f. Tese (Doutorado em Geografia) Faculdade de Ciências e Tecnologia, Universidade Estadual Paulista, Presidente Prudente, 2013.

NEVES NETO, C. C.; HESPANHOL, A. N. O desenvolvimento rural no Brasil e em Portugal: os casos do Programa de Microbacias em São Paulo e da Iniciativa Leader em Portugal. In: Revista Ateliê geográfico, Goiânia, v. 8, n. 1, abr. 2014, p. 74-102.

Disponível em:

$<$ http://www.revistas.ufg.br/index.php/atelie/article/view/29112/16529>. Acesso em: 10 ago. 2015.

SANTOS, J. C dos. O sistema agroindustrial do leite na região de Presidente Prudente-SP. 168 f. Dissertação (Mestrado em Geografia) - Faculdade de Ciências e Tecnologia, Universidade Estadual Paulista, Presidente Prudente, 2004.

SARON, F. A. Os efeitos dos programas de desenvolvimento rural para o apoio à agricultura familiar no Noroeste paulista: limites, desafios e perspectivas. 243. f. Dissertação (Mestrado em Geografia) - Faculdade de Ciências e Tecnologia, Universidade Estadual Paulista, Presidente Prudente, 2014.

SARON, F. A.; JACINTO, R. M. M.; HESPANHOL, A. N. Limites e desafios para o desenvolvimento rural em Portugal e no Brasil: os efeitos dos programas LEADER e PRONAT. In: CUNHA, L.; JACINTO, R. M. M. (Coord.). Paisagens e dinâmicas territoriais em Portugal e no Brasil: as novas geografias dos países de Língua Portuguesa. Guarda: Centro de Estudos Ibéricos, v. 26, 2014.

SILVA, J. A nova dinâmica da agricultura brasileira. 2. ed., Campinas: UNICAMP. IE, 1998. 
SILVA, K. R. D.; SILVA, L. A. C. Análise da comercialização e do impacto do PAA e PNAE na condição de vida das famílias agricultoras de Bananeiras, na Paraíba, Universidade Federal da Paraíba, Universidade Aberta do Brasil, 2011. Disponível em: $<$ http://portal.virtual.ufpb.br/bibliotecavirtual/files/analise_da_comercializaaao_e_do_i mpacto_do_paa_e_pnae_na_condiaao_de_vida_das_famalias_agricultoras_de_bananeir as_na_paraaba_1343924527.pdf>. Acesso em: 17 set. 2014.

SILVA, R. P. Produção do espaço e reestruturação produtiva do setor de laticínios no Rio Grande do Norte. 308. f. Dissertação (Mestrado em Geografia) - Universidade Federal do Rio Grande do Norte, Natal, 2014.

SORJ, B. Estado e classes sociais na agricultura brasileira. Rio de Janeiro, Editora Guanabara, 1986.

SOUZA, L. B. Organizações da agricultura familiar no Estado de São Paulo e sua experiência de fornecimento para o PNAE. In: BELIK, W.; CORÁ, M. A. J. (Org.). Projeto Nutre SP: análise da inclusão da agricultura familiar na alimentação escolar no Estado de São Paulo. São Paulo: Instituto Via Pública, 2012, p. 31-45.

TRICHES, R. M.; SCHNEIDER, S. Alimentação Escolar e Agricultura Familiar: reconectando o consumo à produção. Revista Eletrônica Saúde e Sociedade, v. 19, n. 04, São Paulo, 2010, p. 933-945. Disponível em:

$<$ http://www.scielo.br/scielo.php?script=sci_arttext\&pid=S0104-12902010000400019>. Acesso em: 20 ago. 2012.

TURPIN, M. E. A alimentação escolar como vetor de desenvolvimento local e garantia de segurança alimentar e nutricional. Dissertação (Mestrado em Economia) - Universidade Estadual de Campinas, Campinas, 2008.

VELOSO, F. Políticas públicas no município de Junqueirópolis (SP): o PRONAF e o PAA. 249 f. Dissertação (Mestrado em Geografia) - Faculdade de Ciências e Tecnologia, Universidade Estadual Paulista, Presidente Prudente, 2011.

VILLAR, B. S.; SCHWARTZMAN, F.; JANUARIO, B. L.; RAMOS, J. F. Situação dos municípios do Estado de São Paulo com relação à compra direta de produtos da agricultura familiar para o Programa Nacional de Alimentação Escolar (PNAE). In:

Revista Brasileira Epidemiol, São Paulo - SP, v. 16, n. 1, p. 223 - 226, 2013.

Disponível em: < http://www.scielosp.org/pdf/rbepid/v16n1/1415-790X-rbepid-16-010223.pdf>. Acesso em: 15 set. 2014.

Recebido em 29/10/2015.

Aceito para publicação em 04/06/2016. 